\title{
KREATIVNOST U SPORTU - NOV PRISTUP ISTRAŽIVANJU
}

\author{
Miloš Miloševićí, \\ Irena Ristić2 \\ 1 Univerzitet Singidunum, \\ Beograd, Srbija \\ ${ }^{2}$ Fakultet dramskih umetnosti, \\ Univerzitet umetnosti u Beogradu, \\ Beograd, Srbija
}

Odgovorno lice:

Miloš Milošević

e-pošta:

mmilosevic@singidunum.ac.rs
Rezime:

Cilj ovog rada je predstavljanje novog validnog eksperimentalnog pristupa u istraživanju kreativnosti i razmatranje potencijala njegove implementacije u istraživanjima sporta. Za ocenu kreativnosti produkta konstruisani su koeficijent kreativnosti (kao količnik mogućih i dobijenih različitih odgovora) i koeficijent izuzetnosti (kao količnik broja 1 i broja subjekata koji su dali isti odgovor). Radi povećanja brzine i preciznosti merenja, i eliminacije sistemskih grešaka napravljena su softverska rešenja Pic Rotator 1.0. i unapređena verzija Pic Rotator 2.0. Ovakav pristup omogućava prevazilaženje postojećih metodoloških ograničenja i empirijsku validaciju teorijskih postavki psihologije kreativnosti u domenu sporta, ali i pokušaj da se odgovori na otvorena pitanja o prirodi kreativnosti u sportu, a posebno njene povezanosti sa sportskim rezultatom.

Ključne reči:

koeficijent kreativnosti, merenje, softver, pobuđenost, vreme reakcije.

\section{UVOD}

Ako se ima u vidu da u naučnoj i široj stručnoj zajednici postoji konsenzus da je kreativnost jedan od odlučujućih faktora koji determiniše sportski rezultat, kako u kolektivnom tako i u individualnom sportu, da je važna i u sportskim igrama kao i u bazičnim disciplinama [1, 2, 3], čudi izostanak dubljeg i detaljnijeg istraživanja ove teme, pogotovo u okviru empirijskih studija koje su metodološki dosledno i precizno izvedene.

Odgovor se može potražiti u prirodi studija kreativnosti, u kojima još uvek nije postignut zadovoljavajući stepen validnosti i objektivnosti merenja ishoda kreativnog procesa (kreativnosti produkata) [4], kao preduslova za naučno istraživanje kreativnog mišljenja, i strukture i dinamike kreativnog procesa. Za razliku od testova divergentnog mišljenja koji se bave merenjem kreativnosti kao skupa sposobnosti, a čija su validnost i pouzdanost relativno visoke i potvrđene u brojnim istraživanjima, postupci koji su fokusirani na merenje kreativnosti produkata u znatno većoj meri su predmet kritike. Merenje kreativnosti produkta najčešće se zasniva na nezavisnim procenama eksperata, postupkom konsenzualne tehnike procene (CAT), u kojoj eksperti iz domena koji je predmet istraživanja, bez posebne pripreme i uputstava ocenjuju kreativnost produkta. 
Da bi se ovakvo merenje smatralo validnim, neophodno je da se dobije visok stepen intersubjektivne saglasnosti procenjivača koji se iskazuje vrednošću Kronbahovog alfa koeficijenta [Chronbah $\alpha \geq 0,70$ ]. Iako je u brojnim empirijskim istraživanjima potvrđena validnost CAT merenja, zbog čega se već koristi kao standardna procedura u studijama kreativnosti, ovoj tehnici, a pogotovo praksi njene primene, mogu se uputiti brojne metodološke i praktične zamerke $[4,5]$.

Angažovanje eksperata iz oblasti koja je predmet istraživanja, kao preduslov valjanosti merenja konsenzualnom tehnikom, u praksi je teško ispuniti iz ekonomskih razloga. Zbog toga je čest slučaj da se za nezavisne procene angažuju „kvazieksperti” (daroviti praktičari, istraživači-početnici ili studenti) ili čak naivni subjekti. Ovaj postupak umnogome kompromituje validnost merenja, pogotovo kod istraživanja produkata visokog stepena složenosti [6]. Sama ocena kreativnosti ishoda kreativnog mišljenja i kreativne prakse može biti dugačak, zahtevan i zamoran proces, a i kod najbolje organizovanih istraživanja ocene ipak ostaju subjektivne i pod uticajem preferencija, iskustva i eksplicitnih, kao i implicitnih teorijskih ubeđenja procenjivača. Kao posledica, prilikom implementacije CAT merenja, javlja se nužnost redukovanja početnog uzorka procenjivača, kako bi se postigao zadovoljavajući nivo intersubjektivne saglasnosti. Ipak, čak i kada se postigne, ni visok stepen intersubjektivne saglasnosti, potvrđen analizom pouzdanosti, ne može biti garant kontrole interferirajućih promenljivih [4].

$S$ druge strane, glavne odlike novih digitalnih, informacionih i komunikacionih tehnologija, i njihovog ubrzanog razvoja, jesu upravo preciznost, dostupnost i demokratičnost upotrebe, što se lako može uočiti u svim područjima njihove primene. One sa sobom nose potencijal za unapređenje istraživačke prakse, zbog ekonomičnosti a posledično i proširenja obima istraživanja, ali i zbog povećanja nivoa objektivnosti i preciznosti merenja kao preduslova validnosti istraživanja [4].

Opisani potencijal nedovoljno je iskorišćen u polju društveno-humanističkih nauka, kako u studijama kreativnosti tako i u studijama sporta, u čijem preseku se nalazi predmet interesovanja ovog rada. Stoga se nužno nameće pitanje da li je uz primenu digitalnih i informacionih tehnologija moguće razviti nov, ekonomičan i objektivan način merenja kreativnosti produkta, koji bi obezbedio preciznije proučavanje prirode kreativnog procesa u sportu. Da li psihometrijska efikasnost i egzaktnost može biti dostignuta i u istraživanju sportske kreativnosti?
Cilj ovog rad je da izloži nov metodološki pristup u istraživanju kreativnosti, fokusiran pre svega na merenje kreativnosti produkta - pristup koji je svoju primenu već pronašao u studijama kreativnog mišljenja i procesa umetnika, uz analizu njegove potencijalne primene $\mathrm{u}$ istraživanjima sporta.

\section{KOEFICIJENTI KREATIVNOSTI}

Kada se želi konstruisati merni instrument koji bi omogućio objektivan način ocene kreativnosti produkta potrebno je prvo uzeti u obzir dva kriterijuma oko kojih postoji konsenzus u studijama kreativnosti [7]. Prvi je kriterijum novine, stvaranje nečega novog i jedinstvenog, što se procenjuje kao učestalost u odnosu na referentnu grupu, pa se može izjednačiti sa Gilfordovim (Joy Paul Guilford) faktorom originalnosti [8]. Drugi je kriterijum funkcionalnosti produkovanog rešenja, odnosno njegove celishodnosti. Ovaj kriterijum nije razmatran u studijama divergentnog mišljenja, ali je njegovo razmatranje izuzetno važno u studijama sporta, gde svaki pokret ili potez može uticati na postizanje krajnjeg cilja u okviru sportskog takmičenja. Različita veoma jedinstvena i originalna rešenja i potezi u sportu moraju proći test celishodnosti, podesnosti, korisnosti i primenljivosti u odnosu na postizanje željenog rezultata, da bi se mogla označiti kao kreativna. Ovde ipak treba praviti razliku između uspešnosti rešenja (postizanja cilja) i njihove funkcionalnosti. Rešenje se može označiti kao nefunkcionalno iako je spletom okolnosti dovelo do sportskog rezultata, ili kao funkcionalno iako je krajnji rezultat izostao.

Rezultati studija, ipak, daju prednost novini, kao pouzdanijem prediktoru kreativnosti od funkcionalnosti [9], pa se funkcionalnost često označava kao kriterijum drugog reda, čija je uloga diferenciranje smislenih i besmislenih visoko inovativnih ideja i postupaka [10]. Ovde se javlja i problem što je svaka procena funkcionalnosti (korisnosti) uvek i vrednosna procena koja je podložna promeni, pogotovo pod uticajem vremena, novih informacija, kulture i društva. Mnoge vredne ideje i postupci kroz istoriju najpre su bili procenjeni kao besmisleni, da bi njihova prava vrednost bila shvaćena mnogo kasnije. Moguće rešenje ovog problema je definisanje kreativnosti kao intencionalne novine [11], što omogućuje razlikovanje novine koja na predviđen način dovodi do cilja od novine koja to čini slučajno, spletom okolnosti. Ovakva reformulacija pojma kreativnosti vrlo je praktična zbog toga što omogućuje izdvajanje bizarnih od zaista kreativnih odgovora. Ipak, budući da se u 
sportu odluke donose u izuzetno kratkom vremenskom intervalu, često instinktivno ili automatski, oštro razlikovanje intencionalnih od neintencionalnih reakcija nije uvek moguće.

Ako se u obzir uzmu iskustva psihometrijskog pristupa (studije divergentnog mišljenja) i reformulacija pretpostavljenih kriterijuma kroz koncept intencionalne novine, moguće je konstruisati numerički izraz stepena kreativnosti. Kvantifikacija se zasniva na objektivnom i jednostavnom merenju, na osnovu statističke procene originalnosti koja je relativna i operacionalizuje se kao učestalost sličnih ili istovetnih odgovora u uzorku ispitanika. Ovim se, kao i u prethodnom razmatranju, prednost daje prvom kriterijumu - novini. Ipak, da bi se ispoštovao i drugi kriterijum, pre procene originalnosti neophodno je sprovesti još jedan dodatni postupak.

Prilikom procene kreativnosti odgovora (produkata) u zadacima heurističkog tipa dobijenih $u$ istraživanju, odgovori se svrstavaju u kategorije po sličnosti, po principu ocenjivanja otvorenih upitnika. Nakon toga, odgovori procenjeni kao izuzetni (svrstani sami u jednu kategoriju), u drugom koraku procenjuju se kao intencionalna (smisleni odgovor na problemsku situaciju i plod racionalnog mišljenja) ili neintencionalna novina (nasumično ili bizarno ponašanje).

Nefunkcionalni i nasumični odgovor, odnosno odgovor ocenjen kao neintencionalna novina, pridružuje se grupi najmanje originalnih (najučestalijih) odgovora, odnosno najbrojnijoj kategoriji. Opciono, ispitanik koji često daje neintencionalne odgovore isključuje se iz dalje obrade.

Iako postupak kategorizacije na prvi pogled deluje kao nedovoljno objektivan, uz postavljanje jasnih pravila i procedura prilikom kategorisanja, i uz njihovo poštovanje i pridržavanje u izvođenju merenja, subjektivnost se može svesti na minimum, čime se postiže zavidan stepen objektivnosti i validnosti. To je i razlog zbog čega se ovaj postupak sve češće koristi u empirijskim studijama [12].

Nakon izvršene kategorizacije, koeficijent kreativnosti se izračunava kao količnik dobijenih i mogućih različitih odgovora na nivou promenljive [4,5], što je skladu sa Gilfordovim faktorima fluentnosti i fleksibilnosti divergentog mišljenja [12]:

$\mathrm{KK}=\mathrm{N} / \mathrm{n}$

...gde je KK - koeficijent kreativnosti (na nivou promenljive), $\mathrm{N}$ - broj dobijenih kategorija (različitih odgovora) i n - broj ispitanika u uzorku $[4,5]$
Na sličan način, koeficijent izuzetnosti koji je mera kreativnosti svakog pojedinačnog odgovora, odnosno njegove originalnosti, izračunava se kao količnik broja $1 \mathrm{i}$ broja ispitanika svrstanih $\mathrm{u}$ istu kategoriju (broj ispitanika koji su dali isti odgovor), što je u skladu sa Gilfordovim faktorom originalnosti divergentog mišljenja [12]:

$\mathrm{KIi}=1 / \mathrm{m} \quad \mathrm{i}=1, \ldots \ldots \ldots, \mathrm{n}$

...gde je KIi - koeficijent izuzetnosti pojedinačnog odgovora ispitanika, $\mathrm{m}$ - broj ispitanika svrstanih $\mathrm{u}$ istu kategoriju (broj ispitanika koji su dali isti odgovor) [4,5].

Prosečna vrednost koeficijenata izuzetnosti svih odgovora ispitanika u uzorku na jedan zadatak jednaka je koeficijentu kreativnosti tog zadatka (promenljive), što odgovara rezultatima faktorskih analiza Gilfordovih faktora divergentnog mišljenja koji sugerišu da u osnovi sva tri pomenuta faktora (originalnost, fleksibilnost i fluentnost) leži ista sposobnost [13]

$\mathrm{M}=(\mathrm{KI} 1+\mathrm{KI} 2+\ldots \ldots . . \mathrm{KIn}) / \mathrm{n}=\mathrm{KK}$

...gde je $\mathrm{M}$ - aritmetička sredina kreativnosti pojedinačnih odgovora, KI1, KI2,...,KIn - koeficijenti izuzetnosti pojedinačnih odgovora ispitanika, $\mathrm{n}$ - broj ispitanika i KK - koeficijent kreativnosti promenljive [4,5].

Na primer, ako u eksperimentu učestvuje deset ispitanika od kojih se traži da daju najkreativniji odgovor na jednu problemsku situaciju, i svih deset ispitanika da različit odgovor, onda bi koeficijent kreativnosti na nivou zadatka (promenljive) bio maksimalan $\mathrm{KK}=10 / 10=1$. U drugom slučaju, ako bi na primer, svih deset ispitanika dalo isti odgovor, onda bi koeficijent kreativnosti na nivou zadatka bio minimalan $\mathrm{KK}=1 / 10=0.1$. $\mathrm{U}$ prvom slučaju koeficijent izuzetnosti za svakog ispitanika pojedinačno bio bi isti $\mathrm{KI}=1 / 1=1$, dok bi aritmetička sredina koeficijenata izuzetnosti za svih deset ispitanika bila $\mathrm{M}=(1+1 \ldots 1) / 10=1$. U drugom slučaju koeficijent izuzetnosti za svakog ispitanika bio bi $\mathrm{KI}=1 / 10=0.1$, dok bi aritmetička sredina koeficijenata izuzetnosti za svih deset ispitanika bila $\mathrm{M}=(0.1+0.1 \ldots 0.1) / 10=0.1$. [4]. Naravno u praksi ovakvi ekstremni slučajevi se retko pojavljuju, ali je pomoću njih najlakše ilustrovati predloženi postupak merenja kreativnosti.

Sam postupak znatno je ekonomičniji od konsenzualne tehnike (CAT) i omogućava objektivnije i brže merenje. Takođe, ova vrsta kvantifikacije otvara prostor za primenu kvantitativnih metoda obrade podataka pri zaključivanju. 


\section{Validacija koeficijenata}

U pilotskoj studiji proverene su metrijske karakteristike koeficijenata i upoređene su sa rezultatima dobijenih primenom konsenzualne tehnike procene (CAT). Deskriptivna statistička analiza pokazala je da su greške ocene prosečne vrednosti koeficijenta kreativnosti u populaciji veoma niske i manje od $5 \%$ od prosečne vrednosti u uzorku, naspram preko $13 \%$ kod CAT ocena, dok rezultati analize reliabilnosti pokazuju da i jedan i drugi metod procene kreativnosti imaju približno istu pouzdanost, ali se metod procene preko koeficijenta kreativnosti pokazao znatno postojaniji i pouzdaniji kada se u obzir uzme podela testa na dva dela (split half analiza) [14].

U široj studiji koja je usledila, na uzorku od 59 studenata Fakulteta dramskih umetnosti (FDU) i Visoke škole elektrotehnike i računarstva (VISER), uz upotrebu 40 vizuelnih stimulusa, dobijeni su slični rezultati. Rezultati deskriptivne statističke analize pokazuju da je relativna standardna greška ocene prosečne vrednosti u populaciji od oko $2 \%$ od prosečne vrednosti u uzorku $(\mathrm{M}=.65$, $\mathrm{SE}=.01$ ). Takođe, rezultati pokazuju da distribucija ne odstupa značajno od normalne, a dobijen je i visok stepen pouzdanosti ( $\alpha=.82$ ) na nivou celog uzorka. Dobre metrijske karakteristike dobijene su i na nivou tri poduzorka (FDU umetnici, FDU menadžeri i VISER). Rezultati korelacione analize dokazuju validnost merenja jer je dobijena značajna korelacija visokog stepena sa CAT procenom kreativnosti $(\mathrm{r}=.80, \mathrm{p}<.001)$ [15].

Validacija primene koeficijenata kreativnosti u složenijim problemskim situacijama, odnosno validacija eksperimentalnog postupka uz primenu različitih vrsta stimulusa i zadataka koji se pred ispitanike postavljaju je u toku.

\section{SOFTVERSKO REŠENJE}

Za potrebe bržeg, efikasnijeg, objektivnijeg i validnijeg izvođenja eksperimentalnih sesija, odnosno prikupljanja podataka i njihovu pripremu za obradu napravljeno je softversko rešenje Pic Rotator 1.0. [16].

Na početku eksperimentalne sesije, posredstvom softvera traži se od ispitanika da popuni upitnik sa osnovnim demografskim podacima (ime, prezime, pol, škola, godina studiranja, smer). Opciono, ispitanik može koristiti šifru ukoliko je potrebno da učešće bude anonimno.

Nakon popunjavanja upitnika, softver ispitanika upoznaje sa pravilima i procedurama istraživanja, izlaže mu kratko uputstvo o daljem korišćenju softvera i od ispitanika se traži da se odluči da li želi da nastavi sa eksperimentom. Softverom se ispitanik obaveštava da u svakom trenutku bez posledica može da prekine sa eksperimentom pritiskom na dugme „, $x^{\text {“ }}$, i da u slučaju prekida njegovi dotadašnji rezultati neće biti podvrgnuti daljoj obradi.

Kada se ispitanik složi sa pravilima istraživanja, dobija da uradi dva zadatka, jedan nakon drugog, koji ne ulaze u ukupan uzorak odgovora već imaju funkciju vežbe: omogućuju ispitaniku da savlada korišćenje softvera, kako nivo IT kompetencija ne bi uticao na krajnji rezultat. Ispitanik ne dobija informaciju da prikupljanje podataka još nije otpočelo već i početne zadatke rešava kao da su deo eksperimenta.

U glavnoj fazi ispitivanja, softver na ekranu ispitaniku izlaže test situacije (stimuluse) i od njega traži kreativan odgovor. Test situacije izlažu se nasumičnim redosledom. Ispitanik svoje odgovore upisuje u polje za odgovor a kada je odgovorom zadovoljan pritiska dugme „dalje“. Softver ga pita da li je siguran da želi da pređe na sledeći zadatak i daje mu mogućnost da nastavi sa rešavanjem zadatka ako je dugme za prelazak na sledeći zadatak slučajno pritisnuto.

Kao problemske test situacije na primer mogu poslužiti vizuelni stimulusi kao što su fotografije, dok bi primer kreativnog zadatka u tom slučaju bio da ispitanik smisli najkreativniji naslov za izloženu fotografiju.

Pored beleženja ispitanikovih odgovora i njihov unos u matricu, softver meri i vreme koje protekne od izlaganja test stimulusa do prelaska na sledeću test situaciju, i pridružuje ovaj podatak odgovoru ispitanika. Iako ispitanik rešava test situacije nasumičnim redosledom, odgovori na njih ređaju se u matricu u predeterminisanom rasporedu. Matrica podataka koju softver kreira tokom ispitivanja kompatibilna je sa programima SPSS i Microsoft Excel.

Na kraju izlaganja svih stimulusa softver generiše rečenicu na ekranu kojom se ispitaniku zahvaljuje na saradnji, i prelazi na prvi ekran, dok ispitanik svoje mesto ustupa sledećem ispitaniku.

U unapređenoj verziji softvera Pic Rotator 2.0. [17] olakšano je korisniku (ispitivaču), da sam bira uzorak test stimulusa i da ih po želji menja, unošenjem ili brisanjem slika u folderu.

$\mathrm{Na}$ ovaj način klasična test situacija papir-olovkaštoperica, znatno je olakšana za istraživača, a merenje postaje mnogo preciznije. I proces randomizacije izlaganja stimulusa bez upotrebe softvera predstavljao je 
veliku praktičnu poteškoću i dovodio je do odustajanja ili relativizacije primene ovog principa u istraživanjima. Beleženje odgovora i njihova priprema za obradu takođe je ranije predstavljalo dugotrajan proces prepisivanja (prekucavanja) u kome su greške bile česte. Primenom softverskog rešenja, pojavljuje se mogućnost za brzo i precizno merenje i beleženje reakcija kod velikog uzorka ispitanika.

U sledećem koraku indikativno je korišćenje potencijala interneta i mrežnih platformi prilikom prikupljanja podataka na velikim uzorcima ispitanika [4].

Dok je softver za sada podesan za izlaganje vizuelnih stimulusa u vidu slika, fotografija, crteža i slično, njegovo unapređenje koje će omogućiti korišćenje video i audio stimulusa je u toku.

\section{PREGLED REZULTATA DOSADAŠNJIH ISTRAŽIVANJA}

Do danas je kroz četiri eksperimentalne sesije testiran uzorak od 178 ispitanika, studenata FDU i VISER, od čega je 85 muškaraca i 105 žena, prosečnog uzrasta 21,5 godina. Ispitanici su se sami prijavljivali za učešće u eksperimentima, bili su unapred pismeno i usmeno upoznati sa eksperimentalnim zadacima, da će podaci biti korišćeni isključivo anonimno i da u svakom trenutku mogu da se povuku iz eksperimenta bez ikakvih posledica. Izvođenje eksperimenta odobreno je od Dekanata FDU i VISER, i u skladu je sa Kodeksom profesionalne etike Univerziteta umetnosti u Beogradu, kao i sa Etičkim principima i kodeksom propisanim od strane APA $[5,14,15]$.

Kao vizuelni stimulusi korišćene su 74 fotografije i 105 superponiranih kompozicija napravljenih od po 2 fotografije (duple ekspozicije). Fotografije su preuzete iz IAPS i NAPS baze, koje su konstruisane po principima mernog instrumenta i variraju prema dimenzijama emotivnog doživljaja i kvaliteta emocija. Obe baze prošle su fazu validacije i imaju dobre metrijske karakteristike $[18,19]$.

Dok je kreativnost odgovora bila zavisna promenljiva, kao nezavisne promenljive testirane su: bliskost sadržaja, vreme reakcije, pobuđenost, valenca (hedonički ton), sreća, tuga, strah, iznenađenje, bes i gađenje. Procenu bliskosti sadržaja svakog stimulusa ispitanici su vršili pomoću sedmostepene skale Likertovog tipa.

Analizirajući odgovore ispitanika pronađena je negativna povezanost umerenog stepena između valence i kreativnosti i pozitivna povezanost umerenog stepena između vremena reakcije i kreativnosti [5]. Takođe dobijene su statistički značajne negativne povezanosti umerenog stepena između kreativnosti i bliskosti sadržaja, i pozitivna povezanost kreativnosti i pobuđenosti [15]. Takođe je dobijena i pozitivna povezanost umerenog stepena između kreativnosti i tuge, i kreativnosti i besa, a nešto nižeg stepena između kreativnosti i straha, kreativnosti i iznenađenja, i kreativnosti i gađenja, kao i negativna povezanost umerenog stepena između kreativnosti i sreće [15].

Pronađene su i statistički značajne razlike u povezanosti nezavisnih promenljivih sa kreativnošću kod umetničke, menadžerske i opšte populacije (subuzoraka). Dok pre svega novina deluje stimulativno na kreativnost umetnika, na menadžere najstimulativnije deluju negativne emocije, dok su kod opšte populacije i novina i emocije povezane sa kreativnošću, ali je stepen povezanosti niži nego kod studenata umetnosti i menadžmenta [15].

Superponirani stimulusi pokazali su se kao stimulativniji za kreativni proces od pojedinačnih slika [5]. Kod superponiranih stimulusa pokazan je i statistički značajan efekat kontrasta na dimenziji valence, ali ne i pobuđenosti. Kompozicije kongruentne po valenci (sasvim prijatne ili sasvim neprijatne) rezultuju manje kreativnim naslovima [20].

\section{MOGUĆNOST PRIMENE U ISTRAŽIVANJIMA U SPORTU}

Posebna prednost opisane metodologija jeste što se bez promene može primeniti i na sportskoj populaciju, sa ciljem da se ispita postoji li razlika u prirodi kreativnog procesa sportista i ostalih populacija, kada je $u$ pitanju kreativnost kao opšta (pre svega verbalna) sposobnost. Sa druge strane, mogućnost diferenciranja kreativnih od manje kreativnih sportista u ovakvom eksperimentalnom nacrtu može dati odgovor na pitanje da li je sportska kreativnost (kreativnost u sportu) posebna sposobnost ili je opravdano govoriti o kreativnosti kao opštoj sposobnosti.

Ispitivanje sličnosti i razlika kreativnog mišljenja i kreativnog procesa kod sportista u odnosu na tri opisana subuzorka trenutno je u toku. Istraživanje koje obuhvata uzorak studenata Fakulteta za fizičku kulturu i sportski menadžment Univerziteta Singidunum odnosi se pre svega na širok domen kognitivnih sposobnosti, i može poslužiti kao osnova za buduća istraživanja u užem i specifičnijem domenu motornog učenja i motorne kontrole. 
Da bi se uspešno izvela sledeća planirana faza ovog istraživanja neophodno je prilagođavanje opisane metodologije problemskim situacijama sportskog takmičenja i treninga. U predviđenoj adaptaciji softverskog rešenja kao vizuelni stimulusi koriste se fotografije ili video zapisi sportskih problemskih situacija (realnih mečeva ili simuliranih za potrebe istraživanja) dok se od ispitanika očekuje da odgovori šta bi uradio u datoj situaciji (koji bi bio njegov sledeći potez).

Ako se želi veći stepen sličnosti eksperimentalne i realne situacije, subjekt može na velikom ekranu posmatrati razvoj problemske situacije (konkretne akcije) i na znak eksperimentatora reagovati kao da je u pitanju realna utakmica u kojoj učestvuje. Na primer, ispitanik posmatra snimak košarkaške utakmice kadriran iz subjektivnog plana tako da ispitanik ima utisak direktnog učešća. Eksperimentor mu dodaje realnu loptu u ruke u istom trenutku kada to čini i saigrač na snimku i beleži se šta će ispitanik uraditi. Još veći stepen sličnosti eksperimentalne i sportske situacije može se postići ako se kao stimulusi koriste obučeni subjekti koji su instruisani od strane eksperimentatora da se kreću i reaguju na tačno utvrđen način - simulacija sportskog nadmetanja po principima situacionog treninga.

Primena medija virtuelne realnosti u ovakvom nacrtu dovela bi do još većeg stepena eksperimentalne kontrole uz očuvanje sličnosti eksperimentalne i realne situacije.

Opisana metodologija ocene kreativnosti može se koristiti i u analizi već odigranih mečeva gde bi se izdvajao veći broj sličnih situacija uz praćenje u kojim uslovima sportisti daju kreativnije i manje kreativne odgovore. Na primer indikativno je ispitati uticaj umora, vremenskog intervala meča, vremena provedenog u igri, prisustva publike, grupne dinamike i različitih kontekstualnih datosti na stepen kreativnosti sportista.

Računanja koeficijenta kreativnosti u već opisanoj situaciji košarkaške utakmice posmatrane na ekranu može biti izvedeno u praksi na sledeći način. U trenutku kada dobiju loptu od eksperimentatora četiri ispitanika se opredeljuju da proslede saigraču sa leve strane, tri ispitanika je upućuju preko protivničkog igrača saigraču sa desne strane, dva ispitanika kreću u prodor a jedan ispitanik se odlučuje na šut. U tom slučaju imamo četiri različita odgovora koji po učestalosti variraju, sledstveno i stepen novine se menja u skladu sa originalnošću samog poteza. Ishode možemo porediti sa sledećom eksperimentalnom situacijom kada su na primer svih deset ispitanika loptu uputila saigraču prvom do sebe. U ovoj vrsti analize može se uočiti koje su odlike situacije koje kod sportista ostavljaju više prostora za kreativnost (pregled igre, više ili manje kretanja protivnika i slično). Takođe može se analizom samo prve opisane situacije doći do uvida kada se ispitanici češće odlučuju za manje rizična rešenja a ređe preuzimaju odgovornost, pri čemu prihvatanje rizika i preuzimanje odgovornosti može ukazati na odlike kreativnog reagovanja. Naravno, ovo je samo simplifikovani šematizovani primer sa ciljem ilustracije primene opisane metodologije, u realnim uslovima odnosi su značajno komplikovaniji.

Korišćenje softverskog rešenja i kvantitativna, kao i kvalitativna analiza kreativnosti igrača može pomoći treneru u upoznavanju karakteristika ekipe, dinamike koja tokom igre dominira u pojedinim situacijama, kao i u prepoznavanju uspešnih kombinacija igrača koji produkuju najkreativnija rešenja, ili pak specifičnih situacija u kojima je indikativno podsticati igrače da preuzmu veći stepen slobode u odlučivanju (slobodu u igri).

Ovo su samo neki od primera moguće implementacije opisane metodologije $\mathrm{u}$ ispitivanju kreativnosti $\mathrm{u}$ sportu. Za buduća istraživanja posebno interesantnim čini se uočena veza pobuđenosti i kreativnosti, jer je u brojnim dosadašnjim studijama uočen uticaj baš ove promenljive na sportsko izvođenje i posledično na sportski rezultat $[2,21]$. Veza motoričkih i kognitivnih sposobnosti takođe može biti jedan od predmeta istraživanja, dok se kroz testiranje uzrasnih i polnih razlika mogu uočiti razvojne implikacije ove veze [22]. Takođe kao posebno zanimljive nezavisne promenljive izdvajaju se fiziološke promenljive stanja organizma sportiste (kao što su nuspojave energetskih procesa).

Ispitivanje kreativnog procesa i kreativnosti odgovora u ekstremno skraćenom vremenu reakcije je specifičan problem različitih sportskih disciplina, što se takođe može postići adaptacijom opisane metodologije uz preciznu kontrolu vremenskih intervala. Na primer, za izvođenje zadatka ispitaniku je dostupno određeno vreme reakcije. Ako reakcija izostane ispitanik dobija povratnu informaciju da odgovor nije adekvatan (na primer vidi da mu je protivnik oduzeo loptu, presekao dodavanje ili blokirao šut).

Kompetitivnost sportista može se koristiti u eksperimentima ove vrste gde bi se ispitanici pojedinačno ili ekipno takmičili u kreativnom rešavanju problemskih situacija.

Time što je podjednako podesan za ispitivanje grupne i pojedinačne kreativnosti [3] ovaj pristup čini se posebno pogodnim za istraživanja sporta kao podjednako individualnog i grupnog čina nadmetanja i postignuća, 
jer je vrhunski rezultat $\mathrm{u}$ individualnom sportu uvek plod rada tima koji okružuje sportistu, dok bez individualne izuzetnosti nije moguće postići rezultat u kolektivnom sportu.

Pitanje na koje bi ova vrsta istraživanja mogla da odgovori jeste i povezanost kreativnosti i sportskog rezultata, što ujedno zahteva vrednosno određenje i ponovno promišljanje prirode kreativnosti u sportu. Da li se u sportu kreativnim smatraju samo ona rešenja koja doprinose krajnjem rezultatu? Svedoci smo povećane šematizovanosti sportskih igara gde se od sportista očekuje da bezuslovno i striktno na terenu sprovode zamisli trenera. Iako ovakav pristup često daje sportske rezultate pitanje je da li je to jedina vrednost u sportu ako se on shvata kao deo fizičke kulture.

Predložena istraživanja podjednako će biti dragocena i psihološkoj nauci, u pokušaju odgovora na još uvek otvorena pitanja prirode kreativnosti [23], posebno kada se uzme u obzir do koje mere se u savremenim istraživanjima zanemaruje povezanost nastanka i razvoja motoričkih i kognitivnih procesa i sposobnosti.

\section{ZAKLJUČAK}

$\mathrm{Na}$ osnovu svega iznesenog može se zaključiti da metodologija predložena u ovom radu može pronaći široku primenu u budućim istraživanjima kreativnosti u sportu.

Predloženi način operacionalizacije merenja kreativnosti, kroz razlikovanje kreativnijih od manje kreativnih ishoda, pored toga što nudi veću ekonomičnost uz povećanu objektivnost i validnost istraživanja, otvara vrata daljem unapređenju softvera ka u potpunosti kontrolisanoj softverskoj proceni kreativnosti. Od ove vrste istraživanja korist može imati i informatika u pokušaju kreiranja napredne informacione tehnologije koja simulira složene kognitivne procese.

\section{LITERATURA}

[1] M. Milošević, M. Mudrić, R. Mudrić, M. Milošević, "Using the mind in reprogramming the limits of muscle force in the process of creating champions," Science \& Practice, Vol. 2, No5, 2012, pp. 39-58.

[2] M. Milošević, M. Milošević, Specijal Physical Education, textbook on management the development of the physical integrity and capacity in police officers, Saarbrücken: Lambert academic publishing, 2014.
[3] V. Marković, Plivanje, Beograd: Univerzitet Singidunum, 2017.

[4] M. Milošević, I. Ristić, "New methodology approach to creativity studies," In medias res : časopis filozofije medija, Vol. 5, No. 8, 2016, pp . 1237-1250.

[5] I. Ristić, M. Milošević, "Povezanost kreativne produkcije i emocionalnog doživljaja: postajemo li kreativniji posmatrajući nove neprijatne slike? ," Primenjena psihologija, Vol. 10, No. 3, 2017, pp . 335-353.

[6] F. Galati, "Complexity of Judgment: What Makes Possible the Convergence of Expert and Nonexpert Ratings in Assessing Creativity," Creativity Research Journal, Vol. 27, No. 1, 2015, 24-30.

[7] I. Ristic, B. Skorc, T. Mandic, "Novelty and coherence in group creative processes". Psihologija, Vol. 49, No.3, 2016, pp. 213-229.

[8] J. P. Guilford, The nature of human intelligence, New York: McGraw-Hill, 1967.

[9] M. A. Runco, R. E. Charles, "Judgments of originality and appropriatenessas predictors of creativity," Personality and Individual Differences, No. 15, 1993, pp. 537-546.

[10] J. Diedrich, M. Benedek, E. Jauk, A. Neubauer, "Are creative ideas novel and useful?," Psychology Of Aesthetics, Creativity, And The Arts, Vol. 9, No. 1, 2015, pp. 35-40.

[11] R. W. Weisberg, "On the Usefulness of "Value" in the Definition of Creativity,". Creativity Research Journal, Vol. 27 No. 2, 2015, pp.111-124.

[12] A. Snyder, J. Mitchell, T. Bossomaier, G. Pallier, "The Creativity Quotient: An Objective Scoring of Ideational Fluency," Creativity Research Journal, Vol. 16, No. 4, 2004. pp. 415-420.

[13] K. H. Kim, "Is Creativity Unidimensional or Multidimensional? Analyses of the Torrance Tests of Creative Thinking," Creativity Research Journal, Vol. 18, No. 3, 2006, pp. 251-259.

[14] M. Milošević, I. Ristić, "Konstrukcija i validacija koeficijenta kreativnosti," Saopštenje sa naučnog skupa Empirijska istraživanja u psihologiji XXIII, Beograd. 24.-26. 03. 2017

[15] I. Ristić, M. Milošević, "Neugodni i novi vizualni sadržaji u funkciji kreativnosti: po čemu se studenti umjetnosti razlikuju od ostalih?, "Suvremena psihologija, 2018, (u štampi).

[16] V. Jovanović, I. Matić, M. Milošević, I. Ristić, "Pic Rotator 1.0.," [Computer software]. Beograd: Fakultet dramskih umetnosti, 2015.

[17] V. Jovanović, I. Matić, M. Milošević, I. Ristić, "Pic Rotator 2.0.," [Computer software]. Beograd: Fakultet dramskih umetnosti, 2016. 
[18] P. J. Lang, M. M Bradley, B. N. Cuthbert,. International affective picture system (IAPS): Affective ratings of pictures and instruction manual, Gainesville: University of Florida. 2008.

[19] A. Marchewka, Ł. Żurawski, K. Jednoróg, A. Grabowska, "The Nencki Affective Picture System (NAPS): introduction to a novel, standardized, wide-range, highquality, realistic pictures database," Behavior Research Methods, Vol. 46, No 2, 2014, pp. 596-610.

[20] M. Milošević, I. Ristić, "Creativity and contradictions: How ambivalent images affect the creative production?," Saopštenje sa naučnog skupa Savremeni trendovi u psihologiji, Novi SAd. 19.-21. 10. 2017
[21] V. Marković, Značaj takmičarske analize u poboljšanju rezultata plivača, Sport nauka i praksa, pp. 57 - 67, 2011.

[22] A. Gadžić, V. Marković, Razlike u motoričkim sposobnostima učenika i učenica šestog razreda osnovne škole, Sport nauka i praksa, Vol. 4, No. 2, pp. 5 - 16, 2014.

[23] T, Mandić. I, Ristić, Psihologija kreativnosti. Beograd: Institut za pozorište, film, radio i televiziju, 2013. 